\title{
BLICKDIAGNOSE
}
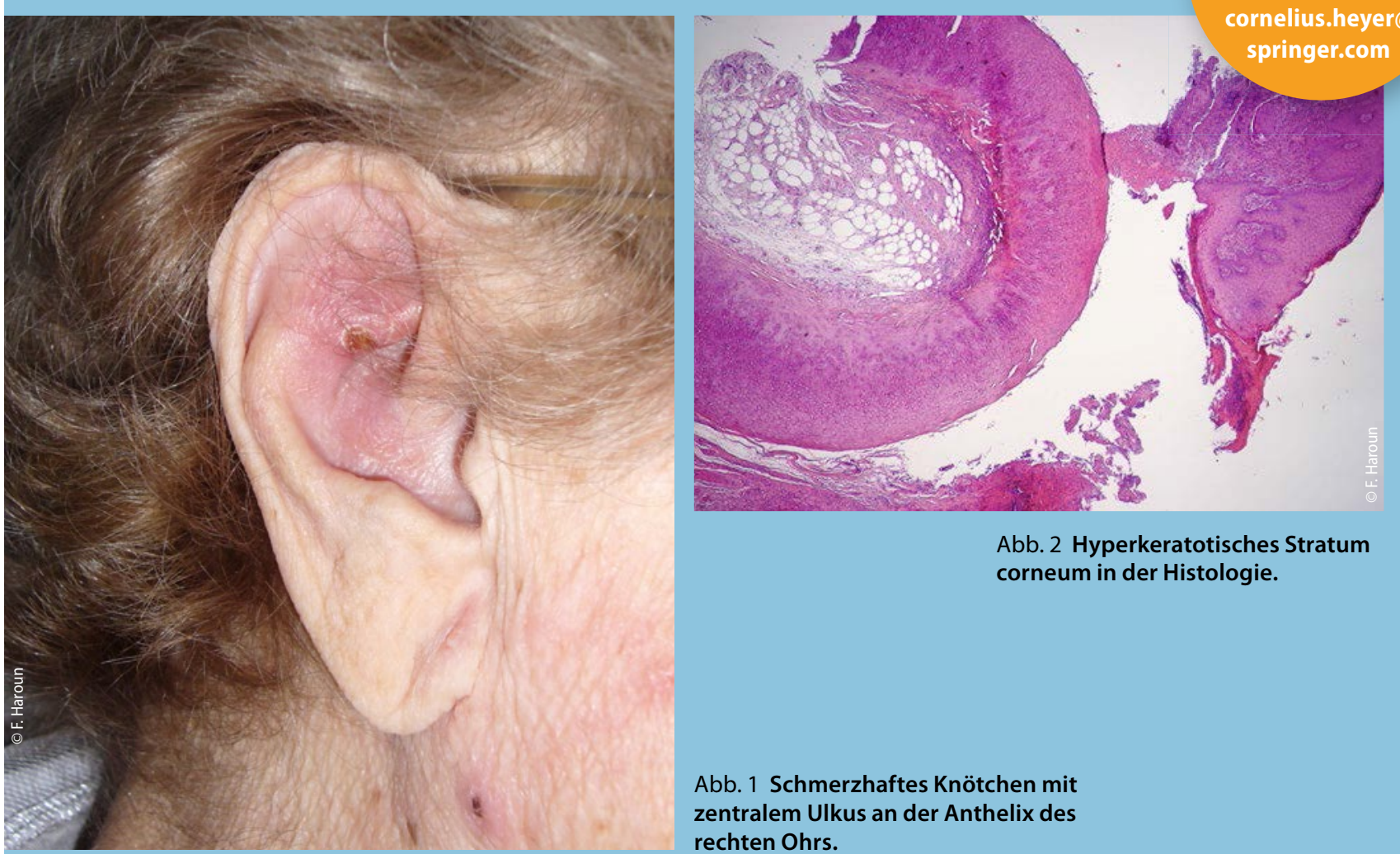

Abb. 2 Hyperkeratotisches Stratum corneum in der Histologie.

\section{Chondrodermatitis nodularis helicis}

\section{Kleines Knötchen - große Schmerzen}

Eine 78-jährige Patientin stellte sich in unserer Praxis wegen eines seit mehreren Wochen bestehenden schmerzhaften Knötchens am rechten Ohr vor (Abb. 1). Sie hatte sich schon bei mehreren $\mathrm{HNO}-\mathrm{A} r z t e n$ vorgestellt und hatte verschiedene Salben verordnet bekommen, die sie ohne Erfolg angewendet hatte. Die Schmerzen waren inzwischen so stark geworden, dass sie nicht mehr auf der rechten Seite schlafen konnte.

Der HNO-Untersuchungsbefund der ansonsten gesunden Patientin zeigte ein leicht rötliches, 4-5 mm großes Knötchen mit zentralem Ulkus an der Anthelix des rechten Ohrs. Das Ulkus war mit einer Kruste bedeckt. Der übrige HNO-Untersuchungsbefund inklusive der Ohrmikroskopie war unauffällig. Daher lag der klinische Verdacht auf eine Chondrodermatitis nodularis helicis $(\mathrm{CNH})$ nahe.

Die Hautveränderung wurde in Lokalanästhesie mit dem darunterliegenden betroffenen Knorpel mit knappem Sicherheitsabstand exzidiert. Der entstandene Defekt wurde unmittelbar danach mit einem freien Lappen gedeckt, der retroaurikulär gewonnen wurde. Die Patientin war nach dem operativen Eingriff sofort beschwerdefrei.
Histologisch zeigte sich ein hyperkeratotisches Stratum corneum mit Parakeratose und Akanthose (Abb. 2). Ein Hinweis auf Malignität konnte nicht gefunden werden. Somit bestätigte sich die Diagnose einer CNH. Differenzialdiagnostisch ist in diesem Fall an Basalzell- oder Plattenepithelkarzinome zu denken. Diese Tumoren sind jedoch im Gegensatz zum CNH normalerweise schmerzlos und werden aus diesem Grund häufig auch sehr spät erkannt.

Typisch für die CNH ist das solitäre Auftreten, hin und wieder wird aber auch eine Manifestation an mehreren Stellen beobachtet. Die betroffenen Patienten sind meist über 50 Jahre alt und männlich. Die $\mathrm{CNH}$ ist bei Männern meistens im Bereich der Helix lokalisiert, während bei Frauen häufiger die Anthelix befallen ist.

\footnotetext{
$\rightarrow$ Firas Haroun

Abteilung für HNO-Heilkunde, Kopf-und Halschirurgie, plastische Operationen, Schilddrüsenchirurgie

St. Barbara-Klinik Hamm, Am Heessener Wald 1, D-59073 Hamm
} 